OPEN ACCESS

Edited by:

Ali H. Eid,

American University of Beirut,

Lebanon

Reviewed by:

Roger Hart,

University of Western Australia,

Australia

David H. Abbott,

University of Wisconsin-Madison,

United States

*Correspondence:

Gonzalo Cruz

gonzalo.cruz@uv.cl

Specialty section:

This article was submitted to Translational Pharmacology, a section of the journal

Frontiers in Pharmacology

Received: 01 December 2019

Accepted: 22 April 2020

Published: 17 June 2020

Citation:

Jorquera G, Echiburú B, Crisosto N, Sotomayor-Zárate $R$, Maliqueo $M$ and Cruz G (2020) Metformin during

Pregnancy: Effects on

Offspring Development and Metabolic Function.

Front. Pharmacol. 11:653. doi: 10.3389/fphar.2020.00653

\section{Metformin during Pregnancy: Effects on Offspring Development and Metabolic Function}

\author{
Gonzalo Jorquera ${ }^{1}$, Bárbara Echiburú ${ }^{2}$, Nicolás Crisosto $^{2,3}$, Ramón Sotomayor-Zárate ${ }^{1}$, \\ Manuel Maliqueo ${ }^{2}$ and Gonzalo Cruz ${ }^{1 *}$ \\ ${ }^{1}$ Centro de Neurobiología y Fisiopatología Integrativa (CENFI), Instituto de Fisiología, Facultad de Ciencias, Universidad de \\ Valparaíso, Valpararaíso, Chile, ${ }^{2}$ Laboratory of Endocrinology and Metabolism, West Division, Faculty of Medicine, University \\ of Chile, Santiago, Chile, ${ }^{3}$ Unit of Endocrinology, Clínica Las Condes, Santiago, Chile
}

Maternal obesity during pregnancy and gestational diabetes mellitus (GDM) are both associated with of several postnatal diseases in the offspring, including obesity, early onset hypertension, diabetes mellitus, and reproductive alterations. Metformin is an oral drug that is being evaluated to treat GDM, obesity-associated insulin resistance, and polycystic ovary syndrome (PCOS) during pregnancy. The beneficial effects of metformin on glycemia and pregnancy outcomes place it as a good alternative for its use during pregnancy. In this line of thought, improving the metabolic status of the pregnant mother by using metformin should avoid the consequences of insulin resistance on the offspring's fetal and postnatal development. However, some human and animal studies have shown that metformin during pregnancy could amplify these alterations and be associated with excessive postnatal weight gain and obesity. In this minireview, we discuss not only the clinical and experimental evidence that supports the benefits of using metformin during pregnancy but also the evidence showing a possible negative impact of this drug on the offspring's development.

Keywords: metformin, pregnancy, polycystic ovary syndrome, diabetes mellitus, postnatal, bodyweight

\section{INTRODUCTION}

Metformin has been one of the most successful drugs for the treatment of type 2 diabetes mellitus in the world. The pleiotropic effects of metformin have led scientists to propose its use for the treatment of other pathologies including polycystic ovary syndrome (PCOS) (Legro et al., 2013; Johnson, 2014) and cancer (Chae et al., 2016). In addition, the lack of severe adverse effects and its low cost have positioned metformin as one of the drugs with the best risk/benefit ratio.

Metformin is an orally used biguanide absorbed mainly in the small intestine through organic cation transporters (Markowicz-Piasecka et al., 2017). It enters the enterohepatic circulation arriving in the liver, which is one of its main targets, and then, it is distributed throughout the body entering the cells through organic cation transporters (Markowicz-Piasecka et al., 2017). These transporters are also expressed in the placenta, thus permitting the transport of metformin into the fetal blood. Once inside the cell, metformin inhibits the Complex I within the mitochondrion, decreasing the efficiency of the electron transport chain, leading to a decrease in ATP generation. 
Metformin also inhibits AMP deaminase, increasing AMP levels through this pathway. The increase in the AMP : ATP ratio activates the AMP-activated protein kinase (AMPK), a serine/ threonine kinase that has a wide range of intracellular effects leading to the activation and inhibition of catabolic and anabolic pathways, respectively (Herzig and Shaw, 2018). Some of the pathways regulated by AMPK are lipogenesis, gluconeogenesis, mechanistic target of rapamycin (mTOR), and NF kappa B signaling, among others. [For a review regarding metformin mechanisms of action please see (Foretz et al., 2019)].

Recently, several studies have analyzed the use of metformin as an alternative to treat gestational diabetes mellitus (GDM), PCOS during pregnancy and even maternal obesity during pregnancy. Here, we review both the evidence supporting the use of metformin during pregnancy along with studies in humans and animal models regarding the long-term effects of metformin in the offspring.

\section{USE OF METFORMIN DURING PREGNANCY}

\section{Gestational Obesity}

Obesity during pregnancy is associated with a greater mortality and morbidity of both mother and child (Leddy et al., 2008). Obesity during pregnancy is associated with a higher risk for pregnancy loss, preterm delivery, hypertension, preeclampsia, and GDM (Lynch et al., 2008). Moreover, gestational obesity is also related to fetal macrosomia (Cedergren, 2004). On the other hand, obesity during pregnancy increases five times the risk of stillbirths and is associated with placental dysfunction (Nohr et al., 2007). Randomized, double-blind, and placebo-controlled trials, using metformin (1,000 to $3,500 \mathrm{mg}$ per day starting during first trimester) have shown a slight reduction in maternal weight gain in normoglycemic obese pregnant women (Elmaraezy et al., 2017; Dodd et al., 2018; Dodd et al., 2019). However, metformin administration is accompanied with gastrointestinal side effects including nausea, diarrhea, and vomiting (Chiswick et al., 2015; Dodd et al., 2019). The risk to develop GDM is not reduced (Chiswick et al., 2015; Sales et al., 2018; Dodd et al., 2019), but one study reports lower serum levels of C-reactive protein and interleukin-6, with a significant reduction in the risk to develop preeclampsia (Syngelaki et al., 2016). Yet, these effects are not associated with an improvement in insulin sensitivity (Balani et al., 2017). Metformin does not reduce the incidence of large for gestational age newborns, nevertheless, it reduces the risk of neonatal intensive care unit admissions (Chiswick et al., 2015; Elmaraezy et al., 2017; D'Ambrosio et al., 2019; Dodd et al., 2019). Therefore, the beneficial effects of metformin on maternal and neonatal health when used in gestational obesity are still under debate and its prescription should be cautious.

\section{Gestational Diabetes}

The prevalence of GDM varies between $10 \%$ and $20 \%$ according to the diagnostic criteria, ethnicity, and personal and family history
(DeSisto et al., 2014; Chiefari et al., 2017; Bashir et al., 2018). Approximately 1 out of 7 pregnancies is affected (International Diabetes Federation, 2017; Chow et al., 2018). GDM is associated with short- and long-term sequelae on both, mother and offspring (Dall et al., 2014; Farrar et al., 2017). Dietary intervention is the primary treatment (Crowther et al., 2005; Landon et al., 2009) and insulin is the classical pharmacotherapy for GDM. However, metformin has gained wide acceptance and has been recommended as a safe alternative to insulin for the treatment of GDM (Hod et al., 2015) (Guidelines N. Diabetes in Pregnancy. NICE Guide 2015. https://www.nice.org.uk/guidance/ng3). The Society for Maternal-Fetal Medicine (SMFM) recently published that in women with GDM in which hyperglycemia cannot be managed by medical nutrition therapy, metformin is a reasonable and safe first-line pharmacologic alternative to insulin. (SMFM Publications Committee, 2018).

Several studies showed reduced weight gain in women with GDM treated with metformin vs. those treated with insulin, along with a reduction of severe hypoglycemia and pregnancyinduced hypertension (PIH) (Rowan et al., 2008; Alqudah et al., 2018). A systematic review and meta-analysis revealed that metformin is better than insulin in reducing both, maternal weight gain during pregnancy and the frequency of $\mathrm{PIH}$, with no changes in the frequency of hypoglycemia and preeclampsia (Gui et al., 2013). In addition, recent randomized controlled trials (RCT) suggest that metformin could be used to treat or prevent preeclampsia (Romero et al., 2017). Interestingly, the Metformin in Gestational Diabetes ( $\mathrm{MiG}$ ) study showed a higher acceptability for metformin than insulin, despite the gastrointestinal side effects produced by metformin (Rowan et al., 2008). However, metformin has a high percentage of ineffectiveness in the management of glycemia in GDM patients and $46 \%$ of women in metformin group needed to incorporate insulin into their treatment (Rowan et al., 2008). A study in a retrospective cohort of Qatar women with GDM observed that metformin in comparison with nutritional therapy, reduces some adverse effects of GDM on pregnancy outcomes, such as maternal weight gain, risk of macrosomia, and neonatal hypoglycemia (Bashir et al., 2018). It is important to note that metformin has been proposed as a safe medication without teratogenic effects (Ainuddin et al., 2015; Jiang et al., 2015; Given et al., 2018). To date, several studies have shown that metformin therapy has greater benefits compared with insulin and glibenclamide as GDM treatments, such as lower risk of large for gestational age babies or macrosomia, neonatal hypoglycemia, and admission to neonatal intensive care units (Rowan et al., 2008; Butalia et al., 2017; Farrar et al., 2017). Although others have observed deleterious effects of metformin, such as an increased rate of preterm birth (Rowan et al., 2008; Su and Wang, 2014). Nevertheless, a recent systematic review shows an absence of metformin associated increase in the rate of preterm delivery, caesarean section or risk of small for gestational age babies (Butalia et al., 2017).

Metformin use has shown more favorable pregnancy outcomes when compared to a controlled diet, but the efficacy when compared to the effects of insulin, is still under debate. 
While a meta-analysis of six RCT concluding that metformin use in GDM is not significantly associated with adverse maternal or neonatal outcomes (Su and Wang, 2014), the evidence also fails to confirm a higher beneficial effect of metformin compared to the use of insulin. Although the use of metformin in pregnancy is not supported by many international clinical guidelines, its use has increased recently (Rowan et al., 2008; Priya and Kalra, 2018). Recommendations regarding metformin use in pregnancy vary widely, partly because of its ability to cross the placenta (Simmons et al., 2004; Hyer et al., 2018; Simeonova-Krstevska et al., 2018). While some studies found no clear evidence of any adverse outcomes related to the use of metformin for the treatment of GDM in pregnancy (Priya and Kalra, 2018; Maple-Brown et al., 2019), others have reported comparable outcomes to insulin therapy (Rowan et al., 2008). Many medical associations have suggested that insulin should be considered as a first-line agent for managing GDM (Lindsay and Loeken, 2017), along with appropriate lifestyle changes (Lindsay and Loeken, 2017). Despite the considerable evidence suggesting that metformin is safe during pregnancy, long-term safety data are still needed (Simmons et al., 2004; Hyer et al., 2018; SimeonovaKrstevska et al., 2018).

\section{Polycystic Ovary Syndrome}

PCOS is a highly prevalent endocrine-metabolic dysfunction (5$10 \%$ of women in reproductive age) which is associated with metabolic disturbances that have a high impact in cardiometabolic diseases, such as insulin resistance (Dunaif et al., 1989; Franks, 1995; Holte, 1996) and pancreatic beta cell dysfunction with subsequent development of type 2 diabetes (O'Meara et al., 1993; Ehrmann et al., 1999; Legro et al., 1999). PCOS patientsdiagnosed according to the NIH criteria (presence of hyperandrogenism and chronic anovulation) (Zawadski and Dunaif, 1992) - have an increased metabolic risk. In this group the prevalence of glucose intolerance is $23 \%$ to $35 \%$ and $4 \%$ to $10 \%$ for type 2 diabetes (T2D) (O'Meara et al., 1993; Ehrmann et al., 1999; Legro et al., 1999; Ehrmann et al., 2005). According to the Rotterdam definition, the diagnosis of PCOS may be established with at least 2 out of 3 criteria: hyperandrogenism, oligo-anovulation, and a polycystic ovary on ultrasound image (Group R. E. A. S. P. C. W., 2004), generating four different phenotypes. Hyperandrogenism is the main factor for the development of metabolic and cardiovascular alterations (Azziz et al., 2009; Fauser et al., 2012).

PCOS patients have an increased risk for pregnancy complications. A 2011 a meta-analysis shows that the odds ratio for different pregnancy complications is significantly increased in PCOS patients compared to controls. Most recently, Palomba et al. found a 3- to 4-fold increase in PIH and preeclampsia, 3-fold increase in GDM, and a 2-fold higher chance for premature delivery (Palomba et al., 2015) among PCOS patients. Authors concluded that characteristics associated to PCOS, such as hyperandrogenism, obesity, insulin resistance, and other metabolic abnormalities, may contribute to the increased risk of obstetric and neonatal complications (Palomba et al., 2015). Women with PCOS have shown placental inflammation, placental thrombosis and infarction during pregnancy, added to villous immaturity and nucleated fetal red blood cells (Koster et al., 2015). These alterations may be signs of vascular damage and fetal hypoxia which could be linked to complications in PCOS pregnancies (Koster et al., 2015).

Metformin has been evaluated in several studies in the context of PCOS pregnancy. It has been reported an $18.7 \%$ incidence of miscarriage in non-treated PCOS women, $10 \%$ in women who received metformin up to 32 weeks of gestation, and $0 \%$ in those who received metformin throughout pregnancy $(\mathrm{p}<0.006)$ (Nawaz et al. 2008). A 2012 meta-analysis reports that in five out of seven studies analyzed, metformin reduces the development of GDM in pregnant women with PCOS (Ghazeeri et al 2012). As the methodologies were different and there were no RCT at that time, these results are inconclusive. The biggest and more accurate RCT regarding this issue was performed by Vanky et al. Their work showed no effect of metformin on the prevalence of GDM and preeclampsia and only a significant reduction in preterm delivery in a subgroup of compliant patients in the per protocol analysis (Vanky et al., 2010). A second RCT from the same group reported a reduction in the risk of late miscarriage and preterm birth with no difference in the prevalence of GDM (Lovvik et al., 2019). The effects of metformin on preterm delivery are of notable interest given the known association of preterm delivery with neonatal mortality, respiratory distress syndrome, cerebral palsy, gastrointestinal and cardiovascular disorders, retinopathy of prematurity, high cost related to prenatal care, among many other consequences (Behrman and Butler, 2007). Indeed, some clinical trials have started to evaluate the effect of metformin to avoid preterm delivery in patients with preeclampsia (Cluver et al., 2019).

We compared the effects of metformin treatment in a historic PCOS group and compared them to untreated patients in a small cohort study. Our results show that the prevalence of GDM drops from $36 \%$ to $14 \%$ (Crisosto et al., 2012). This study was designed to evaluate differences in the offspring of PCOS patients treated and not treated with metformin. Our untreated patient group had an important pathogenic profile, with increased androgen and insulin levels. Metformin use normalized these parameters, and the female offspring of our patients showed a normalization of $\mathrm{AMH}$ levels, a marker illustrating the prevention of ovarian programing. We think metformin worked very well because our PCOS patients had a $36 \%$ prevalence of GDM. Nevertheless, in the first Vanky study (Vanky et al., 2010) untreated patients had the same basal prevalence of our treated group. In that setting, it is difficult to see an effect. Therefore, the usefulness of metformin is not a black and white issue, it depends on the profile and the phenotype of the patient.

\section{POSTNATAL EFFECTS OF METFORMIN EXPOSURE DURING PRENATAL LIFE}

\section{Evidence in Humans Postnatal Effects of Metformin in a PCOS Context}

Few reports have explored the postnatal effects of metformin in humans. These studies have been carried out in children of 
different ages born to mothers with PCOS or GDM during pregnancy, hence comparisons among these results should be done cautiously. The first studies by Glueck et al. in a PCOS US population, did not show differences in growth and motor-social development after 3, 6, 9, 12, and 18 months after birth in children whose mothers were exposed to 1.5 to $2.55 \mathrm{~g}$ /day of metformin during pregnancy (Glueck et al., 2014).

We published that metformin use is able to normalize androgens and insulin levels during pregnancy, and reduce $\mathrm{AMH}$ levels, an ovarian marker associated to a higher risk of PCOS in the female offspring as early as 2 two months of life (Crisosto et al., 2012). Lately, studies carried out in Norwegian children born to women with PCOS receiving $2.0 \mathrm{~g}$ of metformin daily from the first trimester to delivery, show that women who used metformin in pregnancy lost less weight and their infants were heavier than those in the placebo group one year postpartum $(10.2 \pm 1.2 \mathrm{~kg}$ vs $9.7 \pm 1.1 \mathrm{~kg}$ ) (Carlsen et al., 2012). Recently, the same researchers observed that 1-year old females that had been exposed to metformin in utero had a larger head circumference compared to non-exposed girls, a feature not observed in boys. At 4 years of age, both males and females maintain a higher weight with an odds ratio of 2.17 (1.04-4.61) to be overweight/obese (Hanem et al., 2018). Another study in women with PCOS treated with $850 \mathrm{mg}$ of metformin from the first trimester to term, shows that, at 8 years of age, children exposed prenatally to metformin exhibits higher glucose levels and a strong trend towards elevated systolic blood pressure and a lower LDL cholesterol level (Ro et al., 2012).

\section{Postnatal Effects of Metformin in a GDM Context}

In GDM, children at 18 month of age and exposed to metformin are heavier and taller than those exposed to insulin during pregnancy. However, motor, social, or linguistic development did not differ between the groups (Ijas et al., 2015). At 2 years of age, children of the metformin group present with a larger skinfold (mid-upper arm circumferences, subscapular, and biceps skinfold), although fat mass and body fat percentage, assessed by bioimpedance and DEXA, are not different (Rowan et al., 2011; Wouldes et al., 2016). Moreover, in these children, no differences in blood pressure and neurodevelopmental tests are reported (Battin et al., 2015). By 9 years of age, children exposed to metformin evidence larger waist circumferences, waist/height ratio, $\mathrm{BMI}$, and triceps skinfold. Interestingly, fat mass evaluated by DEXA and MRI tends to be higher in the metformin compared to the insulin group, suggesting a higher risk for development metabolic syndrome but with comparable biochemical parameters (Rowan et al., 2018). On the other hand, a study including 1,996 children born to women with GDM treated with metformin and 1,932 treated with insulin shows no differences in child growth and neurodevelopment between both groups (Landi et al., 2019). Also, one study compares the testicular size in prepubertal boys born to mothers who participated in a RCT contrasting metformin with insulin in the treatment of GDM. No differences in testicular size were found from 33 to 85 months of age (Tertti et al., 2016). Finally, a meta-analysis including 10 randomized studies in women with PCOS or GDM with a total of 778 children and a maximal follow-up duration of 9 years shows that children exposed in utero to metformin are heavier than controls, although the BMI z-score are comparable between groups (van Weelden et al., 2018).

\section{Evidence from Animal Models}

Recent studies have analyzed the long-term metabolic effects linked to metformin exposure during prenatal life in animal models. In one of these studies murine dams under regular diet are treated with $300 \mathrm{mg} / \mathrm{kg} /$ day during pregnancy (Salomäki et al., 2013). It finds that intrauterine metformin exposed females, but not males, fed with a regular diet have higher body weight between 4.5 and 7 weeks of age. When the offspring exposed to metformin are fed with a high fat diet (HFD) for 8 weeks, both males and females (at 17 weeks old), demonstrate higher weight gain compared to the offspring of mothers not treated with the drug. The authors also show elevated fasting glucose levels and an impaired glucose tolerance test in males fed with HFD exposed to metformin in prenatal life (Salomäki et al., 2013).

In another article, female mice are fed with a HFD 1 month before mating and during the gestation period and with or without oral administration of metformin 300/mg/day during pregnancy (Salomäki et al., 2014). During the second week of gestation metformin-treated HFD dams exhibit diminished fasting glucose levels compared to those treated with vehicle. Fetuses exposed to metformin are lighter at E18.5 compared to those not exposed. At 10 to 11 weeks old, offspring started a HFD until week 17. Intrauterine exposure of females to metformin and HFD, results in less body weight gain and reduced percentage of fat along with an increased percentage of lean mass compared not exposed prenatally females (Salomäki et al., 2014). In addition, the female offspring of metformin-treated dams present with less weight in all the white adipose tissue (WAT) deposits. In glucose tolerance tests, HFD animals from both genders present with improved glycemic responses when their mothers received metformin during pregnancy (Salomäki et al., 2014). Similar results are observed in a study where pregnant mice have access, during the whole pregnancy, to regular diet and water in which metformin is disolved $(5 \mathrm{mg} / \mathrm{ml}$ ) (Gregg et al., 2018). Young 6-week-old males exposed prenatally to metformin show a better glucose management during an intraperitoneal glucose tolerance test, and they secrete more insulin after glucose injection compared to controls (Gregg et al., 2018). In females exposed in utero to metformin, there were no changes in metabolic parameters at young ages, but at 1 to 2 years old, they have a better glucose tolerance response. Finally, these authors have shown that $\beta$-cells from males exposed to metformin secrete more insulin after high glucose $(22 \mathrm{mM})$ or $\mathrm{KCl}(30 \mathrm{mM})$ stimulation in an in vitro assay (Gregg et al., 2018).

A different article studied the ability of prenatal metformin treatment to diminish signs of metabolic syndrome in the offspring (Tain et al., 2018). Rat dams received a diet high in fructose during the gestation and lactation periods. A group of mothers were treated with metformin $500 \mathrm{mg} / \mathrm{kg} /$ day by gastric gavage. Only male offspring were selected, because males are 
prone to develop hypertension compared to females. Male offspring were fed with control or high fat/high sucrose diet (HFS) after weaning. Twelve-week-old males fed with HFS developed hypertension with an increase of $15 \mathrm{~mm} \mathrm{Hg}$ in mean arterial pressure compared to controls, and the increase in blood pressure was prevented by prenatal metformin exposure (Tain et al., 2018).

We published a study in which HFD fed pregnant rats had access to water in which metformin was dissolved, 1 week before mating, during pregnancy and nursing (Álvarez et al., 2018). Doses were estimated at 160 to $200 \mathrm{mg} / \mathrm{kg} /$ day. We found that body weights of the female offspring exposed to metformin were higher compared to those not exposed, from day 1 to day 60 of age (Álvarez et al., 2018). This difference disappeared after day 60. Females exposed to metformin also had increased retroperitoneal WAT depots, hyperleptinemia, and a tendency to hyperinsulinemia at 2 months old (Álvarez et al., 2018).

Other studies have explored the reproductive function in the offspring of mothers treated with metformin during pregnancy. Recent research has established that prenatal exposure to metformin (300 mg/kg/day to pregnant mice dams) induces a reduction in testicular size in fetal and neonatal states with a significant reduction in the Sertoli cell population (Tartarin et al., 2012). At long term, exposure to metformin during gestation and lactation induces a reduction in sperm count in male rats at 110 days after birth (Forcato et al., 2017). In addition, we observed that metformin treatment ( 1 week before mating until weaning) in HFD-fed rat dams improved ovarian function in the adult female offspring (Álvarez et al., 2018). Moreover, our study showed that prenatal metformin treatment was not able to prevent early puberty onset, induced by an in utero obesogenic environment. However, the treatment reduced the number of antral follicles, follicular cysts, and multi-oocyte follicles in the ovaries of the adult female offspring of obese mothers treated with metformin, which could be useful for diminishing the risk of PCOS development (Álvarez et al., 2018).

\section{REFERENCES}

Álvarez, D., Ceballo, K., Olguín, S., Martinez-Pinto, J., Maliqueo, M., Fernandois, D., et al. (2018). Prenatal metformin treatment improves ovarian function in offspring of obese rats. J. Endocrinol. 239 (3), 325-338. doi: 10.1530/JOE-18-0352

Ainuddin, J. A., Karim, N., Zaheer, S., Ali, S. S., and Hasan, A. A. (2015). Metformin treatment in type 2 diabetes in pregnancy: an active controlled, parallel-group, randomized, open label study in patients with type 2 diabetes in pregnancy. J. Diabetes Res. 2015, 325851. doi: 10.1155/2015/325851

Alqudah, A., McKinley, M. C., McNally, R., Graham, U., Watson, C. J., Lyons, T. J., et al. (2018). Risk of pre-eclampsia in women taking metformin: a systematic review and meta-analysis. Diabetes Med. 35 (2), 160-172. doi: 10.1111/dme.13523

Azziz, R., Carmina, E., Dewailly, D., Diamanti-Kandarakis, E., Escobar-Morreale, H. F., Futterweit, W., et al. (2009). The Androgen Excess and PCOS Society criteria for the polycystic ovary syndrome: the complete task force report. Fertil. Steril. 91 (2), 456488. doi: 10.1016/j.fertnstert.2008.06.035

Balani, J., Hyer, S., Syngelaki, A., Akolekar, R., Nicolaides, K. H., Johnson, A., et al. (2017). Association between insulin resistance and preeclampsia in obese nondiabetic women receiving metformin. Obstet. Med. 10 (4), 170-173. doi: 10.1177/1753495X17725465

Bashir, M., Aboulfotouh, M., Dabbous, Z., Mokhtar, M., Siddique, M., Wahba, R., et al. (2018). Metformin-treated-GDM has lower risk of macrosomia compared

\section{CONCLUDING REMARKS}

The use of metformin as a first-line drug during pregnancy is still controversial. However, it is important to note that the specific features of each patient (PCOS, hyperandrogenism, GDM, low adherence to insulin, risk of preeclampsia) are important to consider when estimating the risk/benefits ratio. The beneficial effects of metformin on pregnancy outcomes are clear in GDM and PCOS pregnancies with insulin resistance. However, the postnatal long-term effects require more evidence. Metformin appears to prevent ovarian developmental programming, but it could be associated to an increased bodyweight and metabolic derangements both in humans and rodents. In this context, the use of metformin during pregnancy has to be analized according to the risk/benefit ratio on each specific group of patients, while waiting for better evidences.

\section{AUTHOR CONTRIBUTIONS}

GJ and RS-Z reviewed data in animal models. BE, NC, and MM reviewed data of human studies. GC coordinated and organized the entire manuscript. GJ and GC edited the final version of the manuscript.

\section{FUNDING}

This work was supported by Centro de Neurobiología y Fisiopatología Integrativa (CENFI), Universidad de Valparaíso. Grant DIUV-CI 01/2006.

\section{ACKNOWLEDGMENTS}

We thank to Dr. Cecilia Silva from Centro de Estudios Científicos (CECS), Valdivia, Chile for reviewing the manuscript.

to diet-treated GDM- A retrospective cohort study. J. Matern. Fetal. Neonatal. Med. 1-141. doi: 10.1080/14767058.2018.1550480

Battin, M. R., Obolonkin, V., Rush, E., Hague, W., Coat, S., and Rowan, J. (2015). Blood pressure measurement at two years in offspring of women randomized to a trial of metformin for GDM: follow up data from the MiG trial. BMC Pediatr. 15, 54. doi: 10.1186/s12887-015-0372-1

R. E. Behrman and A. S. Butler (Eds.) (2007). Preterm Birth: Causes, Consequences, and Prevention (Unated States of America: National Academy of Sciences).

Butalia, S., Gutierrez, L., Lodha, A., Aitken, E., Zakariasen, A., and Donovan, L. (2017). Short- and long-term outcomes of metformin compared with insulin alone in pregnancy: a systematic review and meta-analysis. Diabetes Med. 34 (1), 27-36. doi: 10.1111/dme.13150

Carlsen, S. M., Martinussen, M. P., and Vanky, E. (2012). Metformin's effect on first-year weight gain: a follow-up study. Pediatrics 130 (5), e1222-e1226. doi: 10.1542/peds.2012-0346

Cedergren, M. I. (2004). Maternal morbid obesity and the risk of adverse pregnancy outcome. Obstet. Gynecol. 103 (2), 219-224. doi: 10.1097/ 01.AOG.0000107291.46159.00

Chae, Y. K., Arya, A., Malecek, M. K., Shin, D. S., Carneiro, B., Chandra, S., et al. (2016). Repurposing metformin for cancer treatment: current clinical studies. Oncotarget 7 (26), 40767-40780. doi: 10.18632/oncotarget.8194 
Chiefari, E., Arcidiacono, B., Foti, D., and Brunetti, A. (2017). Gestational diabetes mellitus: an updated overview. J. Endocrinol. Invest. 40 (9), 899-909. doi: 10.1007/s40618-016-0607-5

Chiswick, C., Reynolds, R. M., Denison, F., Drake, A. J., Forbes, S., Newby, D. E., et al. (2015). Effect of metformin on maternal and fetal outcomes in obese pregnant women (EMPOWaR): a randomised, double-blind, placebocontrolled trial. Lancet Diabetes Endocrinol. 3 (10), 778-786. doi: 10.1016/ S2213-8587(15)00219-3

Chow, C. K., Ramasundarahettige, C., Hu, W., AlHabib, K. F., Avezum, A.Jr., Cheng, X., et al. (2018). Availability and affordability of essential medicines for diabetes across high-income, middle-income, and low-income countries: a prospective epidemiological study. Lancet Diabetes Endocrinol. 6 (10), 798808. doi: 10.1016/S2213-8587(18)30233-X

Cluver, C., Walker, S. P., Mol, B. W., Hall, D., Hiscock, R., Brownfoot, F. C., et al. (2019). A double blind, randomised, placebo-controlled trial to evaluate the efficacy of metformin to treat preterm pre-eclampsia (PI2 Trial): study protocol. BMJ Open 9 (4), e025809. doi: 10.1136/bmjopen-2018-025809

Crisosto, N., Echiburú, B., Maliqueo, M., Pérez, V., Ladrón de Guevara, A., Preisler, J., et al. (2012). Improvement of hyperandrogenism and hyperinsulinemia during pregnancy in women with polycystic ovary syndrome: possible effect in the ovarian follicular mass of their daughters. Fertil. Steril. 97 (1), 218-224. doi: 10.1016/j.fertnstert.2011.10.002

Crowther, C. A., Hiller, J. E., Moss, J. R., McPhee, A. J., Jeffries, W. S., Robinson, J. S., et al. (2005). Effect of treatment of gestational diabetes mellitus on pregnancy outcomes. N. Engl. J. Med. 352 (24), 2477-2486. doi: 10.1056/NEJMoa042973

D'Ambrosio, V., Brunelli, R., Vena, F., Di Mascio, D., Marchetti, C., Boccherini, C., et al. (2019). Metformin reduces maternal weight gain in obese pregnant women: A systematic review and meta-analysis of two randomized controlled trials. Diabetes Metab. Res. Rev. 35 (6), e3164. doi: 10.1002/dmrr.3164

Dall, T. M., Yang, W., Halder, P., Pang, B., Massoudi, M., Wintfeld, N., et al. (2014). The economic burden of elevated blood glucose levels in 2012: diagnosed and undiagnosed diabetes, gestational diabetes mellitus, and prediabetes. Diabetes Care 37 (12), 3172-3179. doi: 10.2337/dc14-1036

DeSisto, C. L., Kim, S. Y., and Sharma, A. J. (2014). Prevalence estimates of gestational diabetes mellitus in the United States, Pregnancy Risk Assessment Monitoring System (PRAMS), 2007-2010. Prev. Chronic. Dis. 11, E104. doi: $10.5888 /$ pcd11.130415

Dodd, J. M., Grivell, R. M., Deussen, A. R., and Hague, W. M. (2018). Metformin for women who are overweight or obese during pregnancy for improving maternal and infant outcomes. Cochrane Database Syst. Rev. 7, CD010564. doi: 10.1002/14651858.CD010564.pub2

Dodd, J. M., Louise, J., Deussen, A. R., Grivell, R. M., Dekker, G., McPhee, A. J., et al. (2019). Effect of metformin in addition to dietary and lifestyle advice for pregnant women who are overweight or obese: the GRoW randomised, double-blind, placebo-controlled trial. Lancet Diabetes Endocrinol. 7 (1), 1524. doi: 10.1016/S2213-8587(18)30310-3

Dunaif, A., Segal, K. R., Futterweit, W., and Dobrjansky, A. (1989). Profound peripheral insulin resistance, independent of obesity, in polycystic ovary syndrome. Diabetes 38 (9), 1165-1174. doi: 10.2337/diab.38.9.1165

Ehrmann, D. A., Barnes, R. B., Rosenfield, R. L., Cavaghan, M. K., and Imperial, J. (1999). Prevalence of impaired glucose tolerance and diabetes in women with polycystic ovary syndrome. Diabetes Care 22 (1), 141-146. doi: 10.2337/diacare.22.1.141

Ehrmann, D. A., Kasza, K., Azziz, R., Legro, R. S., Ghazzi, M. N., and Group, P. T. S. (2005). Effects of race and family history of type 2 diabetes on metabolic status of women with polycystic ovary syndrome. J. Clin. Endocrinol. Metab. 90 (1), 66-71. doi: 10.1210/jc.2004-0229

Elmaraezy, A., Abushouk, A. I., Emara, A., Elshahat, O., Ahmed, H., and Mostafa, M. I. (2017). Effect of metformin on maternal and neonatal outcomes in pregnant obese non-diabetic women: A meta-analysis. Int. J. Reprod. BioMed. (Yazd) 15 (8), 461-470. doi: 10.29252/ijrm.15.8.461

Farrar, D., Simmonds, M., Bryant, M., Sheldon, T. A., Tuffnell, D., Golder, S., et al. (2017). Treatments for gestational diabetes: a systematic review and metaanalysis. BMJ Open 7 (6), e015557. doi: 10.1136/bmjopen-2016-015557

Fauser, B. C., Tarlatzis, B. C., Rebar, R. W., Legro, R. S., Balen, A. H., Lobo, R., et al. (2012). Consensus on women's health aspects of polycystic ovary syndrome (PCOS): the Amsterdam ESHRE/ASRM-Sponsored 3rd PCOS Consensus Workshop Group. Fertil. Steril. 97 (1), 28-38.e25. doi: 10.1016/j.fertnstert.2011.09.024
Forcato, S., Novi, D. R. B. D., Costa, N. O., Borges, L. I., Góes, M. L. M., Ceravolo, G. S., et al. (2017). In utero and lactational exposure to metformin induces reproductive alterations in male rat offspring. Reprod. Toxicol. 74, 48-58. doi: 10.1016/j.reprotox.2017.08.023

Foretz, M., Guigas, B., and Viollet, B. (2019). Understanding the glucoregulatory mechanisms of metformin in type 2 diabetes mellitus. Nat. Rev. Endocrinol. 15 (10), 569-589. doi: 10.1038/s41574-019-0242-2

Franks, S. (1995). Polycystic ovary syndrome. N. Engl. J. Med. 333 (13), 853-861. doi: 10.1056/NEJM199509283331307

Ghazeeri, G. S., Nassar, A. H., Younes, Z., and Awwad, J. T. (2012). Pregnancy outcomes and the effect of metformin treatment in women with polycystic ovary syndrome: an overview. Acta Obstet. Gynecol. Scand. 91 (6), 658-678. doi: 10.1111/j.1600-0412.2012.01385.x

Given, J. E., Loane, M., Garne, E., Addor, M. C., Bakker, M., Bertaut-Nativel, B., et al. (2018). Metformin exposure in first trimester of pregnancy and risk of all or specific congenital anomalies: exploratory case-control study. BMJ 361, k2477. doi: 10.1136/bmj.k2477

Glueck, C. J., Goldenberg, N., Pranikoff, J., Loftspring, M., Sieve, L., and Wang, P. (2014). Height, weight, and motor-social development during the first 18 months of life in 126 infants born to 109 mothers with polycystic ovary syndrome who conceived on and continued metformin through pregnancy. Hum. Reprod. 19 (6), 1323-1330. doi: 10.1093/humrep/deh263

Gregg, B. E., Botezatu, N., Brill, J. D., Hafner, H., Vadrevu, S., Satin, L. S., et al. (2018). Gestational exposure to metformin programs improved glucose tolerance and insulin secretion in adult male mouse offspring. Sci. Rep. 8 (1), 5745. doi: 10.1038/s41598-018-23965-4

Group, R. E. A.-S. P. C. W (2004). Revised 2003 consensus on diagnostic criteria and long-term health risks related to polycystic ovary syndrome. Fertil. Steril. 81 (1), 19-25. doi: 10.1016/j.fertnstert.2003.10.004

Gui, J., Liu, Q., and Feng, L. (2013). Metformin vs insulin in the management of gestational diabetes: a meta-analysis. PloS One 8 (5), e64585. doi: 10.1371/ journal.pone.0064585

Hanem, L. G. E., Stridsklev, S., Júlíusson, P. B., Salvesen, Ø., Roelants, M., Carlsen, S. M., et al. (2018). Metformin Use in PCOS Pregnancies Increases the Risk of Offspring Overweight at 4 Years of Age: Follow-Up of Two RCTs. J. Clin. Endocrinol. Metab. 103 (4), 1612-1621. doi: 10.1210/jc.2017-02419

Herzig, S., and Shaw, R. J. (2018). AMPK: guardian of metabolism and mitochondrial homeostasis. Nat. Rev. Mol. Cell Biol. 19 (2), 121-135. doi: 10.1038/nrm.2017.95

Hod, M., Kapur, A., Sacks, D. A., Hadar, E., Agarwal, M., Di Renzo, G. C., et al. (2015). The International Federation of Gynecology and Obstetrics (FIGO) Initiative on gestational diabetes mellitus: A pragmatic guide for diagnosis, management, and care. Int. J. Gynaecol. Obstet. 131 (Suppl 3), S173-S211. doi: 10.1016/S0020-7292(15)30007-2

Holte, J. (1996). Disturbances in insulin secretion and sensitivity in women with the polycystic ovary syndrome. Baillieres Clin. Endocrinol. Metab. 10 (2), 221247. doi: 10.1016/S0950-351X(96)80085-1

Hyer, S., Balani, J., and Shehata, H. (2018). Metformin in Pregnancy: Mechanisms and Clinical Applications. Int. J. Mol. Sci. 19 (7). doi: 10.3390/ijms19071954

Ijas, H., Vaarasmaki, M., Saarela, T., Keravuo, R., and Raudaskoski, T. (2015). A follow-up of a randomised study of metformin and insulin in gestational diabetes mellitus: growth and development of the children at the age of 18 months. Bjog 122 (7), 994-1000. doi: 10.1111/1471-0528.12964

International Diabetes Federation (2017). IDF Diabetes Atlas. 8th ed. (Brussels, Belgium). Availble at: https://www.idf.org/e-library/epidemiology-research/ diabetes-atlas/134-idf-diabetes-atlas-8th-edition.html.

Jiang, Y. F., Chen, X. Y., Ding, T., Wang, X. F., Zhu, Z. N., and Su, S. W. (2015). Comparative efficacy and safety of OADs in management of GDM: network meta-analysis of randomized controlled trials. J. Clin. Endocrinol. Metab. 100 (5), 2071-2080. doi: 10.1210/jc.2014-4403

Johnson, N. P. (2014). Metformin use in women with polycystic ovary syndrome. Ann. Transl. Med. 2 (6), 56. doi: 10.3978/j.issn.2305-5839.2014.04.15

Koster, M. P., de Wilde, M. A., Veltman-Verhulst, S. M., Houben, M. L., Nikkels, P. G., van Rijn, B. B., et al. (2015). Placental characteristics in women with polycystic ovary syndrome. Hum. Reprod. 30 (12), 2829-2837. doi: 10.1093/humrep/dev265

Landi, S. N., Radke, S., Engel, S. M., Boggess, K., Stürmer, T., Howe, A. S., et al. (2019). Association of Long-term Child Growth and Developmental Outcomes 
With Metformin vs Insulin Treatment for Gestational Diabetes. JAMA Pediatr. 173 (2), 160-168. doi: 10.1001/jamapediatrics.2018.4214

Landon, M. B., Spong, C. Y., Thom, E., Carpenter, M. W., Ramin, S. M., Casey, B., et al. (2009). A multicenter, randomized trial of treatment for mild gestational diabetes. N. Engl. J. Med. 361 (14), 1339-1348. doi: 10.1056/NEJMoa0902430

Leddy, M. A., Power, M. L., and Schulkin, J. (2008). The impact of maternal obesity on maternal and fetal health. Rev. Obstet. Gynecol. 1 (4), 170-178.

Legro, R. S., Kunselman, A. R., Dodson, W. C., and Dunaif, A. (1999). Prevalence and predictors of risk for type 2 diabetes mellitus and impaired glucose tolerance in polycystic ovary syndrome: a prospective, controlled study in 254 affected women. J. Clin. Endocrinol. Metab. 84 (1), 165-169. doi: 10.1097/ 00006254-199906000-00019

Legro, R. S., Arslanian, S. A., Ehrmann, D. A., Hoeger, K. M., Murad, M. H., Pasquali, R., et al. (2013). Diagnosis and treatment of polycystic ovary syndrome: an Endocrine Society clinical practice guideline. J. Clin. Endocrinol. Metab. 98 (12), 4565-4592. doi: 10.1210/jc.2013-2350

Lindsay, R. S., and Loeken, M. R. (2017). Metformin use in pregnancy: promises and uncertainties. Diabetologia 60 (9), 1612-1619. doi: 10.1007/s00125-017-4351-y

Lovvik, T. S., Carlsen, S. M., Salvesen, O., Steffensen, B., Bixo, M., Gomez-Real, F., et al. (2019). Use of metformin to treat pregnant women with polycystic ovary syndrome (PregMet2): a randomised, double-blind, placebo-controlled trial. Lancet Diabetes Endocrinol. 7 (4), 256-266. doi: 10.1016/S2213-8587(19)30002-6

Lynch, C. M., Sexton, D. J., Hession, M., and Morrison, J. J. (2008). Obesity and mode of delivery in primigravid and multigravid women. Am. J. Perinatol. 25 (3), 163-167. doi: 10.1055/s-2008-1061496

Maple-Brown, L. J., Lindenmayer, G., Barzi, F., Whitbread, C., Connors, C., Moore, E., et al. (2019). Real-world experience of metformin use in pregnancy: Observational data from the Northern Territory Diabetes in Pregnancy Clinical Register. J. Diabetes 11 (9), 761-770. doi: 10.1111/1753-0407.12905

Markowicz-Piasecka, M., Huttunen, K. M., Mateusiak, L., Mikiciuk-Olasik, E., and Sikora, J. (2017). Is Metformin a Perfect Drug? Updates in Pharmacokinetics and Pharmacodynamics. Curr. Pharm. Des. 23 (17), 2532-2550. doi: 10.2174/ 1381612822666161201152941

Nawaz, F. H., Khalid, R., Naru, T., and Rizvi, J. (2008). Does continuous use of metformin throughout pregnancy improve pregnancy outcomes in women with polycystic ovarian syndrome? J. Obstet. Gynaecol. Res. 34 (5), 832-837. doi: $10.1111 /$ j.1447-0756.2008.00856.x

Nohr, E. A., Bech, B. H., Vaeth, M., Rasmussen, K. M., Henriksen, T. B., and Olsen, J. (2007). Obesity, gestational weight gain and preterm birth: a study within the Danish National Birth Cohort. Paediatr. Perinat. Epidemiol. 21 (1), 5-14. doi: 10.1111/j.1365-3016.2007.00762.x

O'Meara, N. M., Blackman, J. D., Ehrmann, D. A., Barnes, R. B., Jaspan, J. B., Rosenfield, R. L., et al. (1993). Defects in beta-cell function in functional ovarian hyperandrogenism. J. Clin. Endocrinol. Metab. 76 (5), 1241-1247. doi: 10.1210/ jcem.76.5.8496316

Palomba, S., de Wilde, M. A., Falbo, A., Koster, M. P., La Sala, G. B., and Fauser, B. C. (2015). Pregnancy complications in women with polycystic ovary syndrome. Hum. Reprod. Update 21 (5), 575-592. doi: 10.1093/humupd/dmv029

Priya, G., and Kalra, S. (2018). Metformin in the management of diabetes during pregnancy and lactation. Drugs Context 7, 212523. doi: 10.7573/dic.212523

Ro, T. B., Ludvigsen, H. V., Carlsen, S. M., and Vanky, E. (2012). Growth, body composition and metabolic profile of 8-year-old children exposed to metformin in utero. Scand. J. Clin. Lab. Invest. 72 (7), 570-575. doi: 10.3109/00365513.2012.712319

Romero, R., Erez, O., Huttemann, M., Maymon, E., Panaitescu, B., Conde-Agudelo, A., et al. (2017). Metformin, the aspirin of the 21st century: its role in gestational diabetes mellitus, prevention of preeclampsia and cancer, and the promotion of longevity. Am. J. Obstet. Gynecol. 217 (3), 282-302. doi: 10.1016/j.ajog.2017.06.003

Rowan, J. A., Hague, W. M., Gao, W., Battin, M. R., Moore, M. P., and Mi, G. T. I. (2008). Metformin versus insulin for the treatment of gestational diabetes. N. Engl. J. Med. 358 (19), 2003-2015. doi: 10.1056/NEJMoa0707193

Rowan, J. A., Rush, E. C., Obolonkin, V., Battin, M., Wouldes, T., and Hague, W. M. (2011). Metformin in gestational diabetes: the offspring follow-up (MiG TOFU): body composition at 2 years of age. Diabetes Care 34 (10), 2279-2284. doi: $10.2337 / \mathrm{dc} 11-0660$

Rowan, J. A., Rush, E. C., Plank, L. D., Lu, J., Obolonkin, V., Coat, S., et al. (2018). Metformin in gestational diabetes: the offspring follow-up (MiG TOFU): body composition and metabolic outcomes at 7-9 years of age. BMJ Open Diabetes Res. Care 6, 1, e000456. doi: 10.1136/bmjdrc-2017-000456
Sales, W. B., Nascimento, I. B. D., Dienstmann, G., Souza, M. L. R., Silva, G. D. D., and Silva, J. C. (2018). Effectiveness of Metformin in the Prevention of Gestational Diabetes Mellitus in Obese Pregnant Women. Rev. Bras. Ginecol. Obstet. 40 (4), 180-187. doi: 10.1055/s-0038-1642632

Salomäki, H., Vähätalo, L. H., Laurila, K., Jäppinen, N. T., Penttinen, A. M., Ailanen, L., et al. (2013). Prenatal metformin exposure in mice programs the metabolic phenotype of the offspring during a high fat diet at adulthood. PloS One 8 (2), e56594. doi: 10.1371/annotation/abe54d92-1f87-4826-a0a5ba55005f99b4

Salomäki, H., Heinäniemi, M., Vähätalo, L. H., Ailanen, L., Eerola, K., Ruohonen, S. T., et al. (2014). Prenatal metformin exposure in a maternal high fat diet mouse model alters the transcriptome and modifies the metabolic responses of the offspring. PLoS One 9 (12), e115778. doi: 10.1371/journal.pone.0115778

Simeonova-Krstevska, S., Bogoev, M., Bogoeva, K., Zisovska, E., Samardziski, I., Velkoska-Nakova, V., et al. (2018). Maternal and Neonatal Outcomes in Pregnant Women with Gestational Diabetes Mellitus Treated with Diet, Metformin or Insulin. Open Access Maced J. Med. Sci. 6 (5), 803-807. doi: 10.3889/oamjms.2018.200

Simmons, D., Walters, B. N., Rowan, J. A., and McIntyre, H. D. (2004). Metformin therapy and diabetes in pregnancy. Med. J. Aust. 180 (9), 462-464. doi: 10.5694/j.1326-5377.2004.tb06024.x

Society of Maternal-Fetal Medicine (SMFM) Publications Committee and Electronic address: pubs@smfm.org (2018). SMFM Statement: Pharmacological treatment of gestational diabetes. Am. J. Obstet. Gynecol. 218 (5), B2-B4. doi: 10.1016/ j.ajog.2018.01.041

Su, D. F., and Wang, X. Y. (2014). Metformin vs insulin in the management of gestational diabetes: a systematic review and meta-analysis. Diabetes Res. Clin. Pract. 104 (3), 353-357. doi: 10.1016/j.diabres.2013.12.056

Syngelaki, A., Nicolaides, K. H., Balani, J., Hyer, S., Akolekar, R., Kotecha, R., et al. (2016). Metformin versus Placebo in Obese Pregnant Women without Diabetes Mellitus. N. Engl. J. Med. 374 (5), 434-443. doi: 10.1056/NEJMoa1509819

Tain, Y. L., Wu, K. L. H., Lee, W. C., Leu, S., and Chan, J. Y. H. (2018). Prenatal Metformin Therapy Attenuates Hypertension of Developmental Origin in Male Adult Offspring Exposed to Maternal High-Fructose and Post-Weaning High-Fat Diets. Int. J. Mol. Sci. 19 (4). doi: 10.3390/ijms19041066

Tartarin, P., Moison, D., Guibert, E., Dupont, J., Habert, R., Rouiller-Fabre, V., et al. (2012). Metformin exposure affects human and mouse fetal testicular cells. Hum. Reprod. 27 (11), 3304-3314. doi: 10.1093/humrep/des264

Tertti, K., Toppari, J., Virtanen, H. E., Sadov, S., and Ronnemaa, T. (2016). Metformin Treatment Does Not Affect Testicular Size in Offspring Born to Mothers with Gestational Diabetes. Rev. Diabetes Stud. 13 (1), 59-65. doi: 10.1900/RDS.2016.13.59

van Weelden, W., Wekker, V., de Wit, L., Limpens, J., Ijäs, H., van WassenaerLeemhuis, A. G., et al. (2018). Long-Term Effects of Oral Antidiabetic Drugs During Pregnancy on Offspring: A Systematic Review and Meta-analysis of Follow-up Studies of RCTs. Diabetes Ther. 9 (5), 1811-1829. doi: 10.1007/s13300-018-0479-0

Vanky, E., Stridsklev, S., Heimstad, R., Romundstad, P., Skogøy, K., Kleggetveit, O., et al. (2010). Metformin versus placebo from first trimester to delivery in polycystic ovary syndrome: a randomized, controlled multicenter study. J. Clin. Endocrinol. Metab. 95 (12), E448-E455. doi: 10.1210/jc.2010-0853

Wouldes, T. A., Battin, M., Coat, S., Rush, E. C., Hague, W. M., and Rowan, J. A. (2016). Neurodevelopmental outcome at 2 years in offspring of women randomised to metformin or insulin treatment for gestational diabetes. Arch. Dis. Child Fetal. Neonatal. Ed. 101 (6), F488-f493. doi: 10.1136/archdischild-2015-309602

Zawadski, J. K., and Dunaif, A. (1992). "Diagnostic criteria for polycystic ovary syndrome: towards a rationale approach," in Polycystic ovary syndrome. Eds. A. D, J. R. G, F. H and G. R. M (Boston: Blackwel Scientific), 377-384.

Conflict of Interest: The authors declare that the research was conducted in the absence of any commercial or financial relationships that could be construed as a potential conflict of interest.

Copyright @ 2020 Jorquera, Echiburú, Crisosto, Sotomayor-Zárate, Maliqueo and Cruz. This is an open-access article distributed under the terms of the Creative Commons Attribution License (CC BY). The use, distribution or reproduction in other forums is permitted, provided the original author(s) and the copyright owner(s) are credited and that the original publication in this journal is cited, in accordance with accepted academic practice. No use, distribution or reproduction is permitted which does not comply with these terms. 